\title{
AUTOLOGOUS PLATELET RICH PLASMA (PRP) VERSUS LEUCOCYTE-PLATELET RICH FIBRIN (L-PRF) IN CHRONIC NON-HEALING LEG ULCERS - A RANDOMISED, OPEN LABELLED, COMPARATIVE STUDY
}

\author{
Azariah Johnson Samuel Pravin¹, V. Sridhar², Balasubramanian Narayana Srinivasan ${ }^{3}$
}

1 Professor and HOD, Department of Dermato-Venereology, Kanyakumari Government Medical College, Asaripallam, Nagercoil.

${ }_{2}^{2}$ Assistant Professor, Department of Dermato-Venereology, Kanyakumari Government Medical College, Asaripallam, Nagercoil. ${ }^{3}$ Assistant Professor, Department of Dermato-Venereology, Kanyakumari Government Medical College, Asaripallam, Nagercoil.

\section{ABSTRACT}

\section{BACKGROUND}

Our aim was to evaluate and compare the efficacy of Platelet-Rich Plasma (PRP) and Leucocyte Platelet Rich Fibrin (L-PRF) in the treatment of chronic non-healing leg ulcers.

\section{MATERIALS AND METHODS}

A randomised, open labelled comparative study was performed on 30 patients with non-healing ulcers of various aetiologies. 15 patients were treated with PRP and 15 patients with L-PRF at weekly intervals for a maximum of 6 treatments. At the end of the 6week period, reduction in size of the ulcers (Area and volume) was assessed.

\section{RESULTS}

Of 30 ulcers, there were 22 venous ulcers, 1 ulcer due to vasculitis, 1 traumatic ulcer, 2 diabetic ulcers and 4 trophic ulcers. The mean duration of healing of the ulcers were 5.7 weeks in L-PRF and $6.5 \mathrm{in}$ PRP $(\mathrm{p}=0.034)$. About $100 \%$ resolution was seen in 11 of the ulcers in L-PRF and 8 of the ulcers in PRP at the end of the 6th treatment (73.3\% vs. 53.3\%).

\section{CONCLUSION}

L-PRF is more efficacious and has a quicker healing rate than PRP, probably due to its anti-inflammatory effects and also protection against infections. L-PRP will be more promising in future than PRP in treating chronic ulcers.

\section{KEYWORDS}

Leg Ulcers, Platelet rich Plasma, Leucocyte Platelet Rich Fibrin.

HOW TO CITE THIS ARTICLE: Pravin AJS, Sridhar V, Srinivasan BN. Autologous platelet rich plasma (PRP) versus leucocyteplatelet rich fibrin (l-PRF) in chronic non-healing leg ulcers - a randomised, open labelled, comparative study. J. Evolution Med. Dent. Sci. 2016;5(102):7460-7462, DOI: 10.14260/jemds/2016/1689

\section{BACKGROUND}

PRP and L-PRF are simple cost-effective procedures for chronic leg ulcers. Platelets release various cytokines and growth factors like Platelet Derived Growth Factor (PDGF), Transforming Growth Factor (TGF), IL-1, Vascular Endothelial Growth Factor (VEGF), Platelet-Derived Angiogenesis Factor (PDAF), Epidermal Growth Factor (EGF), Insulin-Like Growth Factor (IGF), Epithelial Cell Growth Factor (ECGF), fibrinogen, vitronectin, fibronectin and thromboplastin.1,2 This cocktail of GFs is pivotal in modulation of tissue repair and regeneration. The plasma proteins act as a scaffold for the bone, connective tissue and epithelial migration. The placement of a supra-physiologic concentration of autologous platelets (PRP) was found to be useful in enhancing the wound healing in chronic leg ulcers without any adverse events. Platelet Rich Fibrin (PRF) is a second-generation platelet concentrate. L-PRF requires simplified processing without biochemical blood handling, use of bovine thrombin and anticoagulants are not required. ${ }^{3}$ It helps in efficient cell migration and proliferation. It has supportive effect on immune system and also aids in haemostasis.

Financial or Other, Competing Interest: None.

Submission 16-11-2016, Peer Review 10-12-2016,

Acceptance 16-12-2016, Published 22-12-2016.

Corresponding Author:

Dr. Azariah Johnson Samuel Pravin,

No. 80, Henry Road, Nagercoil-629001,

KK District, Tamilnadu.

E-mail: shahilapravin@gmail.com

DOI: $10.14260 /$ jemds/2016/1689

\section{MATERIALS AND METHODS}

Our aim was to evaluate and compare the efficacy of PlateletRich Plasma (PRP) and Leucocyte Platelet Rich Fibrin (L-PRF) in the treatment of chronic non-healing leg ulcers. It was a randomised (1:1), comparative, open labelled study. 30 patients with chronic non-healing ulcers of various aetiologies $(n=30)$ were included in the study. They were divided into two groups (Fig. 1). Group A - Patients who are chosen for PRP and Group B for L-PRF. Our study period was 6 weeks and we followed all cases for another 6 weeks.

After collecting $20 \mathrm{~mL}$ of patient's blood, PRP was prepared by double spin technique and platelet rich fibrin by ultracentrifugation of the blood sample. Then Group A was administered PRP and for Group B L-PRF gel was applied.4,5 The technique was repeated weekly once for 6 weeks. The results were monitored every week through percentage reduction in area and volume of ulcers. In addition, patients will continue to receive standard treatment for the underlying cause.

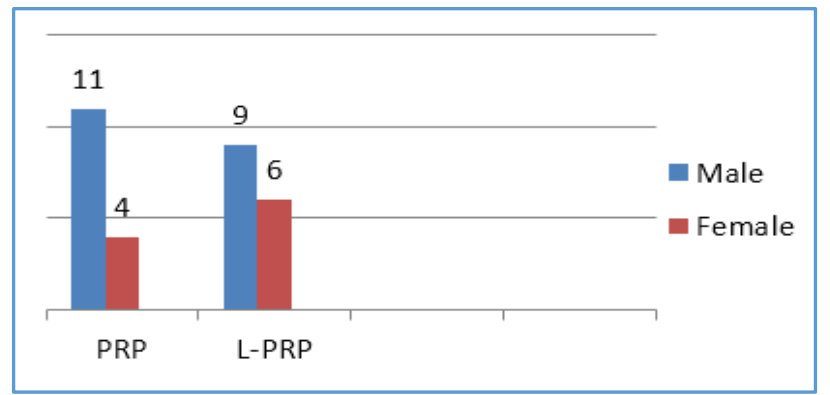

Figure 1 


\section{Inclusion Criteria}

- Patients who have given written informed consent.

- Patients in the age group of 18 - 80 years.

- Wound duration of at least 8 weeks.

- Patients who have received conventional therapies for at least 6 weeks.

- Wound aetiologies include diabetic, arterial or venous ulcer, surgical or traumatic wound and other aetiologies.

\section{Exclusion Criteria}

- $\quad$ Patients with history of bleeding disorders.

- Patients on anti-coagulant medications (Aspirin, Warfarin, Heparin).

- Ulcers with active infection.

- Uncontrolled diabetes.

\section{RESULTS}

Thirty patients with non-healing ulcers of various aetiologies were treated with PRP and L-PRF at weekly intervals for a maximum of 6 treatments. The mean ages of the patients were 43.8 years and 47.1 years in Group A and B respectively. The duration of the ulcers ranged from 2 months to 1 year with a mean of 7.5 months in Group A and 7.2 in Group B (Table 1).

\begin{tabular}{|c|c|c|}
\hline $\begin{array}{c}\text { Duration of the } \\
\text { Ulcer (Months) }\end{array}$ & \multicolumn{2}{c|}{$\begin{array}{c}\text { Number of Ulcers } \\
\text { Group A Group B }\end{array}$} \\
\hline$<3$ & 1 & 0 \\
\hline $3-6$ & 8 & 6 \\
\hline $6-9$ & 4 & 8 \\
\hline $9-12$ & 2 & 1 \\
\hline Total & 15 & 15 \\
\hline \multicolumn{2}{|c|}{ Table 1. Duration of the Ulcer } \\
\hline
\end{tabular}

Of 30 ulcers there were 22 venous ulcers, 1 ulcer due to vasculitis, 1 traumatic ulcer, 2 diabetic ulcers and 4 trophic ulcers (Fig. 2). The mean duration of healing of the ulcers were 5.7 weeks in L-PRF and 6.5 weeks in PRP ( $p=0.034)$. About $100 \%$ resolution was seen in 11 of the ulcers in L-PRF and 8 of the ulcers in PRP at the end of the 6th treatment $(73.3 \%$ vs. $53.3 \%)>90 \%$ improvement in area and volume of the ulcers (Table 2 and 3) seen in 13 and 10 cases in PRF and PRP respectively ( $86.6 \%$ vs. $66.6 \%$ ). Except for very mild pain, there is no side effect noted with both procedures. There were no recurrences during followup.

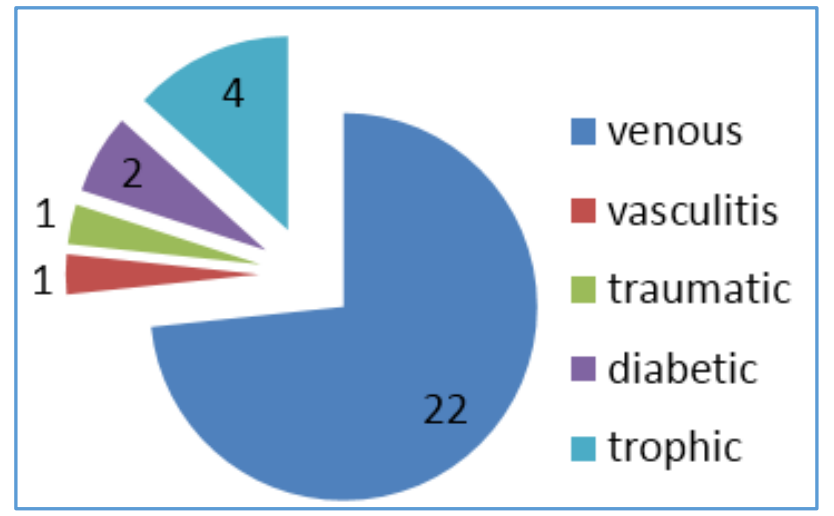

Figure 2

\begin{tabular}{|c|c|c|}
\hline $\begin{array}{c}\text { Percentage Improvement in } \\
\text { the Area at the End of } 6^{\text {th }} \text { Sitting }\end{array}$ & \multicolumn{2}{|c|}{$\begin{array}{c}\text { Number of Ulcers } \\
\text { Group A Group B }\end{array}$} \\
\hline$<60$ & 1 & 0 \\
\hline $61-70$ & 3 & 0 \\
\hline $71-80$ & 0 & 2 \\
\hline $81-90$ & 1 & 0 \\
\hline $91-100$ & 10 & 13 \\
\hline $\begin{array}{r}\text { Table 2. Improvement of Area of the Ulcer } \\
\text { in Percentage at the End of } 6^{\text {th }} \text { Sitting }\end{array}$ \\
\hline
\end{tabular}

\begin{tabular}{|c|c|c|}
\hline $\begin{array}{c}\text { Percentage Improvement in the } \\
\text { Volume at the end of 6 } \\
\text { th } \text { Sitting }\end{array}$ & \multicolumn{2}{|c|}{$\begin{array}{c}\text { Number of Ulcers } \\
\text { Group A Group B }\end{array}$} \\
\hline$<60$ & 0 & 0 \\
\hline $61-70$ & 1 & 0 \\
\hline $71-80$ & 2 & 1 \\
\hline $81-90$ & 2 & 1 \\
\hline $91-100$ & 10 & 13 \\
\hline \multicolumn{2}{|c|}{ Table 3. Improvement of Volume of the } \\
Ulcer in Percentage at the End of 6 ${ }^{\text {th }}$ Sitting \\
\hline
\end{tabular}

\section{L-PRF}
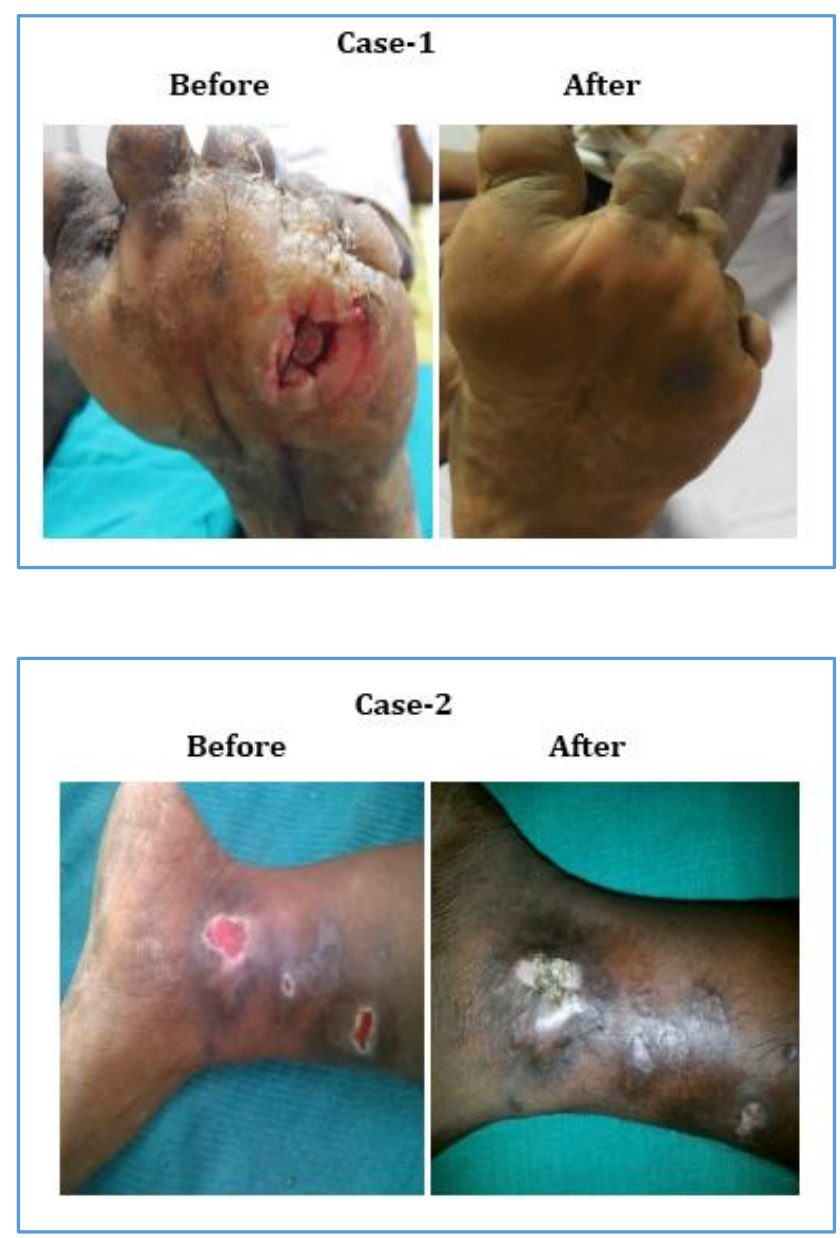
PRP
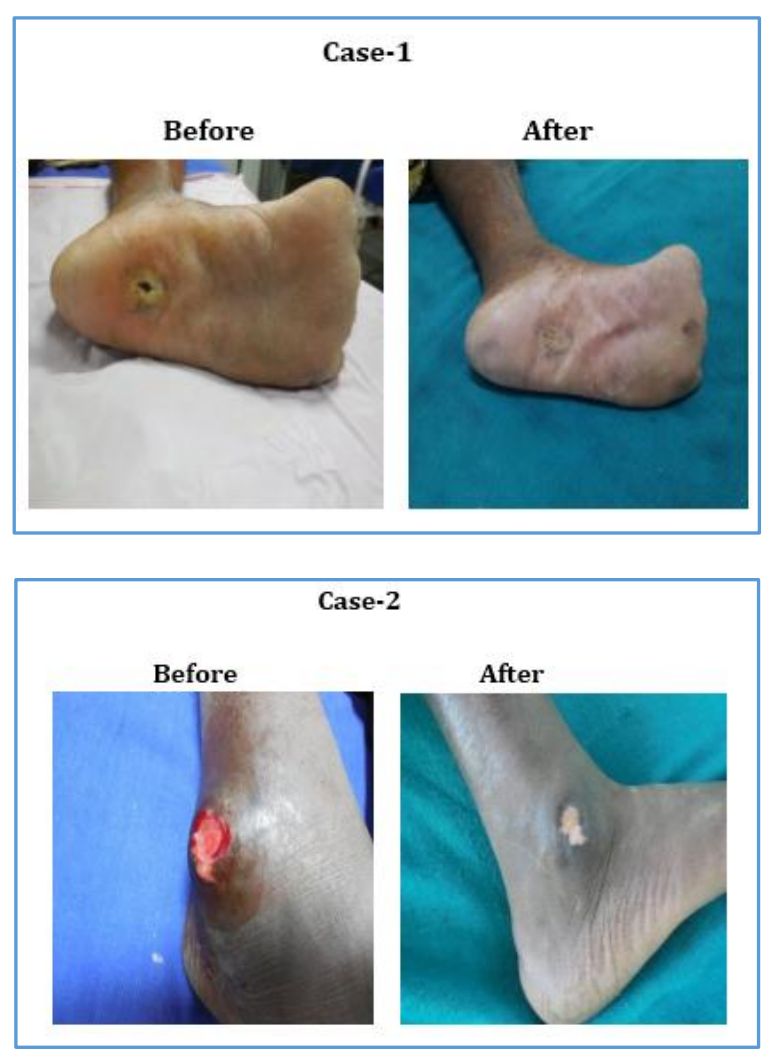

\section{DISCUSSION}

Chronic wounds come with cost and morbidity for patients and society. These wounds are found in all types of healthcare settings and are a challenge for healthcare providers. They are often difficult to treat. Conventional therapies such as dressings, surgical debridement and even skin grafting cannot provide satisfactory healing, since these treatments are not able to provide the necessary GFs to modulate the healing process.

Chronic wounds are a frequent problem in developing countries. Because these wounds lack the necessary GFs for healing; they are often difficult to heal and are frequently complicated by super-infection. PRP and L-PRF contains various GFs that are necessary in wound healing. In addition, the high concentration of leucocytes present in L-PRF is also helpful in preventing infections. ${ }^{6}$

In 1986, Knighton et al ${ }^{7}$ showed that the accelerated epithelialisation of granulation tissue leading to complete repair of chronic non-healing ulcers is attainable by the use of autologous platelet factors. This was the first clinical demonstration that locally acting factors derived from autologous blood promote healing of chronic cutaneous ulcers. In this study, the time to $100 \%$ healing after initiation of Platelet-Derived Wound-Healing Factors (PDWHF) was 7.5 \pm 6.5 weeks. There was a direct correlation between the initiation of PDWHF therapy and 100\% healing. The age of the patients and the location of the ulcers had no statistically significant effect on PDWHF-stimulated wound repair. Platelet-rich plasma enhances wound healing by promoting the healing process secondary to its GFs. These include platelet-derived GF, fibroblast GF, vascular endothelial GF, epidermal GF, insulin-like GF and transforming GF. These GFs stimulate mesenchymal cell recruitment, proliferation, extracellular matrix degeneration and cell differentiation for tissue regeneration. These factors are released from $\alpha$ granules in response to platelet activation by inducers of platelet aggregation.

In a study conducted by Shwetha Suryanarayan et al, ${ }^{8} 24$ patients with 33 ulcers were treated with PRP and the mean duration of healing of the ulcers was 5.6 weeks. Kakudo et al treated five cases of intractable skin ulcer with autologous PRP, among which three ulcers healed completely within 4 weeks and epithelisation of wound occurred within 6.6 weeks on average.

In our study, 15 patients with chronic ulcers were treated with PRP and the mean duration of healing of the ulcers was 6.5 weeks.

A study by Pinto Nelson et al on lower extremity ulcers with L-PRF included 45 patients. All patients showed significant improvements in the healing process and symptomatic relief. L-PRF has the potential to facilitate and accelerate the healing of chronic leg ulcer from different aetiology that were refractory to standard therapy.

In our study, the mean duration of healing of the ulcers were 5.7 weeks in L-PRF. Currently, there are many clinical studies available regarding the beneficial effects of PRP in the treatment of chronic leg ulcers. But we need more scientific data in L-PRF, as there are only few studies available.

\section{CONCLUSION}

Our study shows L-PRF is more efficacious and has a quicker healing rate than PRP, probably due to its anti-inflammatory effects and also protection against infections. L-PRF will be more promising in future than PRP in treating chronic ulcers.

\section{REFERENCES}

1. Sarvajnamurthy S, Suryanarayan S, Budamakuntala L, et al. Autologous platelet rich plasma in chronic venous ulcers: study of 17 cases. J Cutan Aesthet Surg 2013;6(2):97-9.

2. Kakudo N, Kushida S, Minakata T, et al. Platelet-rich plasma promotes epithelialization and angiogenesis in a split thickness skin graft donor site. Med Mol Morphol 2011;44(4):233-6.

3. Naik B, Karunakar P, Jayadev M, et al. Role of PRF in wound healing: a critical review. J Conserv Dent 2013;16(4):284-93.

4. Anitua E, Sanchez M, Nurden AT, et al. New insights into an novel applications for platelet-rich fibrin therapies. Trends in Biotechnology 2006;24(5):227-34.

5. Steenvoorde P, van Doorn LP, Naves C, et al. Use of autologous platelet-rich fibrin on hard-to-heal wounds. Journal of Wound Care 2008;17(2):60-3.

6. Dohan DM, Choukroun J, Diss A, et al. Platelet-rich fibrin (PRF): a second-generation platelet concentrate. Part III: leucocyte activation: a new feature for platelet concentrates? Oral Surg Oral Med Oral Pathol Oral Radiol Endod 2006;101(3):e51-5.

7. Knighton DR, Ciresi KF, Fiegel VD, et al. Classification and treatment of chronic non-healing wounds. Successful treatment with autologous platelet-derived wound healing factors (PDWHF). Ann Surg 1986;204(3):322-30.

8. Suryanarayan S, Budamakuntla L, Khadri SIS, et al. Efficacy of autologous platelet-rich plasma in the treatment of chronic non-healing leg ulcers. Plast Aesthet Res Sep 2014;1(2):65-9. 